\title{
IgG4-related retroperitoneal fibrosis
}

INSERM

\section{Source}

INSERM. (1999). Orphanet: an online rare disease and orphan drug data base. Ig G4related retroperitoneal fibrosis. ORPHA:49041

Retroperitoneal fibrosis (RPF) is characterized by the development of a fibrotic mass surrounding retroperitoneal structures, such as aorta, vena cava, ureters and psoas muscle. 